\title{
PERCEPÇÃO E ATUAÇÃO DOS ESTUDANTES UNIVERSITÁRIOS DA ÁREA DA SAÚDE EM RELAÇÃO À GESTÃO DE RESÍDUOS SÓLIDOS: UM ESTUDO DE CASO NA UNIVERSIDADE DE PERNAMBUCO, RECIFE/PE
}

\author{
Lorrayne Costa de Oliveira ${ }^{1}$ \\ Jéssika Pereira ${ }^{2}$ \\ Iris Barreto ${ }^{3}$ \\ Audenise Cavalcante ${ }^{4}$ \\ Mariana Guenther ${ }^{5}$
}

Resumo: O presente estudo investigou a percepção dos estudantes universitários quanto à separação e descarte de resíduos sólidos, bem como sua atuação como cidadão consciente nesse processo. Com o auxílio de um questionário, foram entrevistados cem estudantes dos cinco cursos da área da saúde oferecidos pela Universidade de Pernambuco (Recife, PE): Ciências Biológicas, Odontologia, Medicina, Educação Física e Enfermagem. De modo geral, os estudantes apresentaram elevado conhecimento sobre reciclagem e destinação apropriada dos resíduos sólidos e a percepção clara da importância da prática sustentável. No entanto, sua atuação individual na gestão dos resíduos ainda é bastante insignificante. Essa distância percebida entre $o$ saber e $o$ fazer pode ser facilmente encurtada através da educação ambiental. A mudança no comportamento da sociedade em relação ao compromisso com o meio ambiente se inicia nos estudantes, e a Universidade, como um local de troca de conhecimento e ideias precisa ir além do papel de formar profissionais em suas áreas específicas.

Palavras-chave: Educação ambiental. Resíduos sólidos. Reciclagem.

\section{PERCEPTION AND PRACTICE OF HEALTH COURSES UNIVERSITY STUDENTS ON SOLID WASTE MANAGEMENT: A CASE STUDY AT THE UNIVERSITY OF PERNAMBUCO, RECIFE/PE}

Abstract: The present study investigated the perceptions of college students regarding the separation and disposal of solid waste as well as its role as a conscious agent in this management process. We interviewed 100 students of the five health courses offered by the University of Pernambuco (Recife, PE): Biological Sciences, Dentistry, Medicine, Nursing and Physical Education. In general, the students demonstrated a high level of knowledge about recycling and proper disposal of solid wastes and a clear understanding of the importance of sustainable practices. However, when it

\footnotetext{
${ }^{1}$ Graduanda em Ciências Biológicas pela Universidade de Pernambuco.

Instituto de Ciências Biológicas, Universidade de Pernambuco. lorrayne.oliveira7@gmail.com

2 Graduanda em Ciências Biológicas pela Universidade de Pernambuco. Instituto de Ciências Biológicas,

Universidade de Pernambuco. jessikapereira.bio@gmail.com

3 Graduanda em Ciências Biológicas pela Universidade de Pernambuco. Instituto de Ciências Biológicas, Universidade de Pernambuco. irisbarretojs@ gmail.com

4 Graduanda em Ciências Biológicas pela Universidade de Pernambuco. Instituto de Ciências Biológicas, Universidade de Pernambuco. audenise.albuquerque@gmail.com

${ }^{5}$ Doutora em Ciências - Oceanografia Biológica pela Universidade de São Paulo.

Profa. Adjunto do Instituto de Ciências Biológicas, Universidade de Pernambuco. Instituto de Ciências Biológicas, Universidade de Pernambuco. mariana.guenther@upe.br
} 
comes to solid waste management in practice, the students do not assume a proactive position. This unbalance between knowledge and action could be easily repaired through environmental education. A change in the society's behavior concerning environmental commitment starts with the students, and the university, as a place of trading knowledge and ideas, needs to go beyond the role of training professionals in their specific areas.

Keywords: Environmental education. Solid wastes. Recycling.

\section{PERCEPCIÓN Y PRÁCTICA DE LOS ESTUDIANTES UNIVERSITARIOS DEL ÁREA DE SALUD EN RELACIÓN CON LA GESTIÓN DE RESIDUOS SÓLIDOS: UN ESTUDIO DE CASO EN LA UNIVERSIDAD DE PERNAMBUCO, RECIFE/PE}

Resumen: El presente estudio investigó la percepción de los estudiantes universitarios sobre la separación y eliminación de residuos sólidos, así como su papel como ciudadano consciente de ese proceso. Con la ayuda de un cuestionario, fueron entrevistados un centenar de estudiantes de los cinco cursos del área de la salud ofrecidos por la Universidad de Pernambuco (Recife, PE): Ciencias Biológicas, Odontología, Medicina, Educación Física y Enfermería. En general, los estudiantes presentaron alto conocimiento sobre el reciclaje y la disposición adecuada de los residuos sólidos y una percepción clara de la importancia de la práctica sostenible. Sin embargo, su desempeño individual en la gestión de residuos es, todavía, bastante insignificante. Esta distancia percibida entre el saber y el hacer se puede acortar fácilmente a través de la educación ambiental. El cambio en el comportamiento de la sociedad en relación con el compromiso con el medio ambiente comienza en los estudiantes, y la universidad, en tanto institución para el intercambio de conocimientos e ideas, debe ir más allá del papel de la formación de profesionales en sus áreas específicas.

Palabras-clave: Educación Ambiental. Residuos Sólidos. Reciclaje.

\section{Introdução}

O aumento do consumo, em todos os setores da sociedade, é um traço marcante dos tempos atuais. A consequente produção de materiais descartáveis para suprir essa crescente demanda gera, portanto, um montante de resíduos que, em sua maioria, não são corretamente tratados. Nesse contexto, os resíduos sólidos merecem especial atenção por apresentarem um processo de degradação (química, física e/ou biológica) extremamente lenta e, assim, perdurarem por muitos anos no ambiente. A atual crise ambiental impulsionada, entre outros, pelo acúmulo desses resíduos nas grandes cidades, aponta para uma necessidade urgente de planejar o seu manejo e destinação de uma forma ambientalmente eficaz, economicamente vantajosa e socialmente acessível.

Diante desse cenário, voltamos nossa atenção para uma reestruturação ideológica dos indivíduos, com vistas à formação continuada de cidadãos comprometidos com o meio ambiente. Essa preocupação com as consequências do consumismo não é apenas crescente, como já assume configurações de emergência (ADÃO, 2005). Uma forte movimentação, científica e cultural, e a formação crítica de cidadãos podem ser vistas nas Instituições de Ensino Superior (IES), e sua abertura para a discussão de temas envolvendo a mitigação dos problemas ambientais se mantém relevante, como a busca de incremento em ações práticas, visando a maior sustentabilidade. A inclusão das mais diversas camadas sociais nas IES tem 
sido uma chave para a construção dessa nova consciência ecológica, unida à divulgação do conhecimento científico pertinente (TAUCHEN; BRANDILI, 2006).

A educação ambiental é uma das ferramentas fundamentais para adequar o homem a seu espaço por meio de incentivos à análise crítica de sua realidade, usando a observação e sensibilização do indivíduo e gerando nele a sensação de pertencimento (JACOBI, 2003). Com o auxílio de um conhecimento teórico prévio, tornam-se possíveis a criação e aplicação de práticas sustentáveis efetivas, estimuladas através de conversas, questionários e instrumentação lúdica (ADÃO, 2005). Há diferentes juízos de valores formados e absorvidos durante e após uma abordagem em Educação Ambiental, dependentes, sobretudo, da percepção ambiental de cada indivíduo, ou seja, do grau de interação e entendimento das responsabilidades deste com seu entorno (BRANDALISE et al., 2009). Desse modo, para que esses métodos educacionais sejam eficazes, é necessária uma investigação prévia aliada a um nivelamento do conhecimento do público-alvo, que facilite a criação de um planejamento de gestão de resíduos apropriado ao contexto.

A gestão integrada dos resíduos sólidos, determinada pela Política Nacional de Resíduos Sólidos - PNRS (BRASIL, 2010), inclui desde a redução da geração de resíduos e coleta seletiva até a reciclagem e reaproveitamento na cadeia produtiva (logística reversa). Este estudo teve como objetivo avaliar a percepção e atuação dos estudantes universitários da área da saúde quanto ao conhecimento referente à gestão dos resíduos sólidos (tipos de materiais recicláveis, coleta e destinação dos vários tipos de resíduos), bem como quanto às atitudes práticas individuais nesse processo. Dentre os cursos escolhidos como alvo, o curso de Ciências Biológicas é o único que apresenta disciplinas mais específicas na área ambiental, servindo, portanto, de comparação aos demais para estimarmos o papel da formação universitária nessa percepção. Este estudo representa, também, uma base de conhecimento para a implementação futura de um plano de gestão de resíduos sólidos no local, cumprindo assim as exigências da PNRS.

\section{Material e Métodos}

O presente estudo foi realizado na Universidade de Pernambuco (UPE), no Campus de Santo Amaro, Recife/PE, durante o mês de maio de 2013. Foi aplicado um questionário, devidamente aprovado pelo Comitê de Ética em Pesquisa da Universidade de Pernambuco (CEP-UPE), a um total de cem estudantes homogeneamente distribuídos nos cinco cursos da área da saúde oferecidos por essa Universidade: Ciências Biológicas (CB), Odontologia (ODONT), Medicina (MED), Educação Física (EF) e Enfermagem (ENF). O questionário foi composto por 12 questões que focaram no entendimento sobre reciclagem e os vários tipos de resíduos, o descarte apropriado dos diferentes resíduos utilizados tanto em casa quanto na Universidade, e a participação ativa individual na separação e destinação correta dos resíduos gerados (Apêndice 1).

De cada curso foram entrevistados vinte alunos, escolhidos aleatoriamente, e as respostas foram anotadas ou gravadas, em comum acordo com o entrevistado. Antes da apresentação do questionário, foi esclarecido o objetivo do projeto e entregue a cada entrevistado o Termo de Consentimento Livre e Esclarecido (TCLE), no qual o mesmo declarou-se de acordo em participar da pesquisa, autorizando a divulgação e a publicação dos dados em periódicos, revistas, apresentações em congressos, workshops ou qualquer evento de caráter científico.

Ao finalizar as entrevistas, o gabarito das questões diretas (excetuando-se as de cunho pessoal) foi enviado aos entrevistados via $e$-mail. As respostas foram compiladas em planilhas eletrônicas e os dados foram analisados em gráficos e tabelas apresentados a seguir. 


\section{Resultados e Discussão}

De modo geral, os estudantes apresentaram elevado conhecimento sobre reciclagem e destinação apropriada dos resíduos sólidos e a percepção clara da importância da prática sustentável. No entanto, sua atuação no processo de separação e descarte dos resíduos ainda é bastante insignificante.

Um dos objetivos deste trabalho foi verificar se havia distinção no conhecimento e postura participativa entre os alunos do curso de Ciências Biológicas (mais voltado para a conservação ambiental) e os demais alunos dos cursos da área de saúde. No entanto, não houve uma grande diferença nas respostas entre os diferentes cursos.

A faixa etária dos entrevistados variou de 17 a 32 anos (23 anos, em média), sendo $65 \%$ residentes na cidade do Recife. A amostra foi bem distribuída em relação à fase do curso (períodos) em que os estudantes se encontravam.

Para iniciar as entrevistas, perguntamos sobre o fato que mais os incomodava no local onde vivem. O lixo, juntamente com a falta de segurança, lazer (incluindo mais áreas verdes) e infraestrutura, esteve entre os principais fatores de incômodo para os entrevistados (Tabela 1). A produção exagerada de resíduos, aliada à sua disposição incorreta, à ineficiência das coletas seletivas (principalmente em áreas periféricas, encostas dos morros e palafitas) e à falta de uma educação ambiental da população, se reflete, de fato, na percepção dos estudantes.

Tabela 1 - Porcentagem de respostas relacionadas ao que mais incomoda o entrevistado em seu local de convívio

\begin{tabular}{lllllll}
\hline & CB & ODONT & MED & EF & ENF & TOTAL \\
\hline Sujeira/lixo & 37 & 25 & 28 & 19 & 19 & 25 \\
Calor & 10 & 4 & 9 & 5 & 6 & 7 \\
Barulho & 13 & 14 & 9 & 11 & 8 & 11 \\
Esgoto & 0 & 0 & 9 & 3 & 22 & 7 \\
Infraestrutura & 23 & 29 & 20 & 35 & 25 & 26 \\
Condições do HUOC & 0 & 11 & 11 & 0 & 11 & 7 \\
Outros & 17 & 18 & 15 & 27 & 8 & 17 \\
\hline
\end{tabular}

* Hospital Universitário Oswaldo Cruz, localizado dentro do Campus Santo Amaro.

Em seguida, propusemos uma autoavaliação prévia do conhecimento em relação ao tema meio ambiente, e uma reflexão sobre o meio de obtenção desse conhecimento (questão 2). Dos entrevistados, a maioria avaliou seu conhecimento entre bom (43\%) e regular (48\%) e a escola, seguida da mídia, foram os principais meios indicados de aquisição desse conhecimento (Fig. 1). 


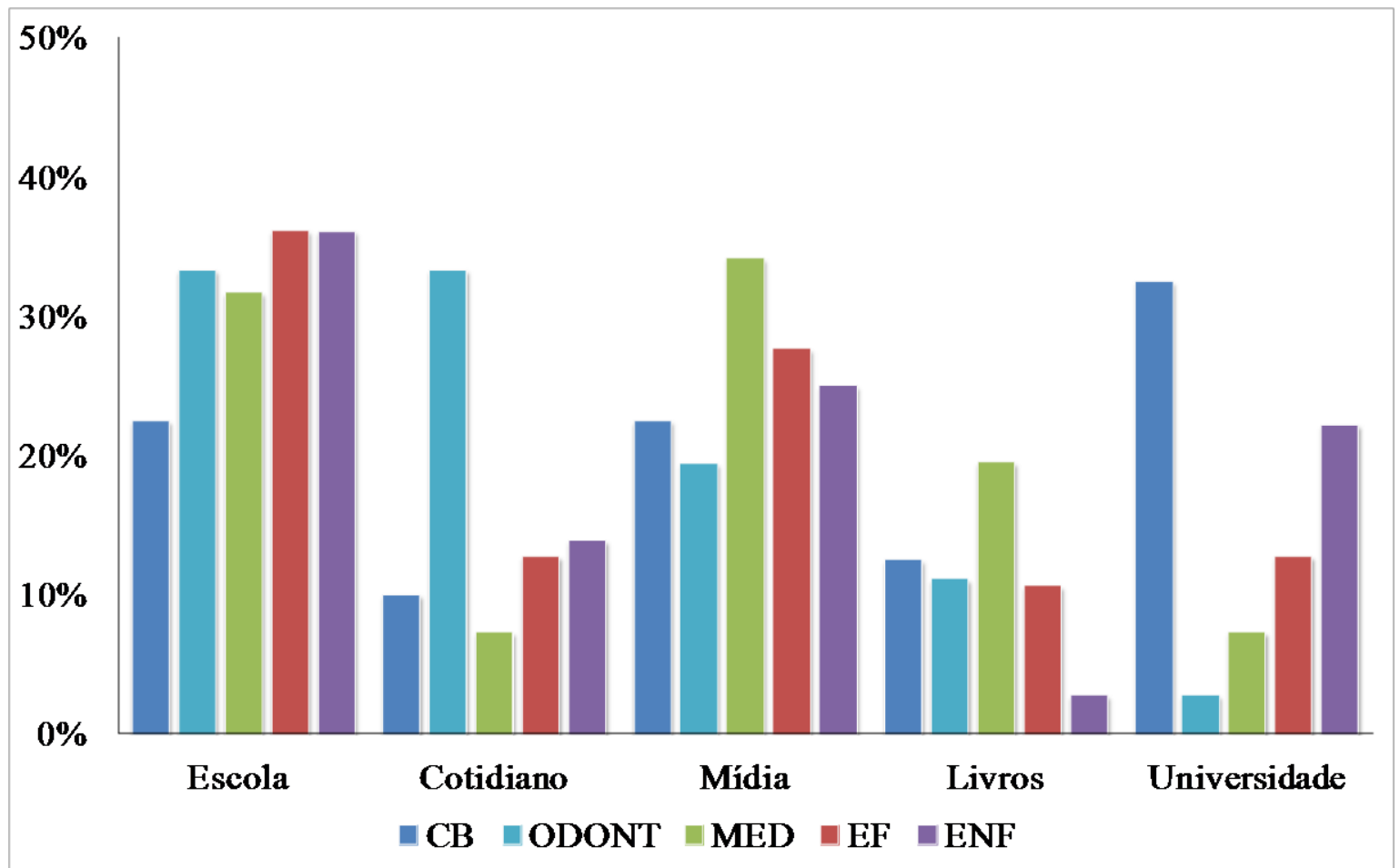

Figura 1 - Variação das respostas dos estudantes universitários sobre as fontes de informação para a obtenção do conhecimento sobre assuntos relacionados ao meio ambiente

Esses dados apontam para o relevante papel da escola, bem como a influência da mídia, na construção da percepção ambiental dos cidadãos. Cabe ressaltar, aqui, o baixo impacto da Universidade nessa formação. Com exceção dos graduandos do curso de Ciências Biológicas, que vivenciam um número maior de disciplinas voltadas para os problemas ambientais, os estudantes dos demais cursos não veem uma participação do que eles vivenciam na Universidade na sua formação enquanto cidadãos ambientalmente conscientes.

Nas três questões seguintes, procuramos investigar o entendimento específico dos participantes sobre reciclagem, resíduos orgânicos e coleta seletiva (Apêndice 1: questões 3, 4 e 5).

\subsection{Reciclagem e coleta seletiva}

Sobre o termo reciclagem (questão 3), apenas 14\% dos entrevistados não souberam responder, sendo a maioria do curso de Enfermagem. No entanto, dos $86 \%$ restantes, $42 \%$ definiram reciclagem como reutilização. Nota-se uma grande dificuldade de distinção entre os termos reciclagem e reutilização.

Reutilização refere-se a utilizar aquele resíduo para um novo fim, sem qualquer modificação na sua composição, como por exemplo, a utilização de potes de vidro para armazenagem de alimentos, ou até a reutilização de uma embalagem para o mesmo fim, como é o caso de garrafas de vidro retornáveis.

A reciclagem, ao contrário, implica em uma modificação física e/ou química do resíduo, que pode ser realizada artesanalmente, como a reciclagem do papel e do papelão, como de forma mais complexa, industrial, como é o caso da reciclagem de garrafas PET ou outros tipos de plástico.

Em relação à coleta seletiva, $35 \%$ dos alunos dos cursos de Odontologia e Educação Física definiram incorretamente, ou não souberam responder, enquanto que a maior percentagem de acerto esteve entre os alunos dos cursos de Ciências Biológicas (85\%) e 
Medicina (100\%). Esses dados indicam que a coleta seletiva não faz parte do dia-a-dia da população entrevistada.

\subsection{Resíduos orgânicos $\mathrm{x}$ recicláveis}

Quanto à relação entre resíduos orgânicos e recicláveis (questão 4), 88\% dos entrevistados definiram corretamente o resíduo orgânico como restos de alimentos em oposição aos resíduos secos. Dos $12 \%$ restantes, $8 \%$ definiram como aquele que não pode ser reciclado (sendo a maioria alunos dos cursos de Ciências Biológicas e Odontologia).

Há, de fato, uma grande confusão entre resíduo não reciclável e resíduo orgânico. A grande maioria dos depósitos de coleta seletiva consiste em cinco compartimentos: papel, vidro, metal, plástico e orgânico. Desse modo, tudo o que não é passível de reciclagem direta é destinado à categoria orgânico o que atrapalha muito a destinação correta dos resíduos, e gera essa confusão na definição. Portanto, a separação ideal deveria consistir em seis recipientes, os quatro já citados destinados à reciclagem, e mais dois onde seriam separados o resíduo orgânico de fato (que seria destinado à compostagem para geração de adubo, e portanto, reciclado) e o resíduo que não tem possibilidade de degradação, reutilização ou reciclagem. Assim, o volume de resíduo gerado sem possibilidade de transformação seria muito menor. De fato, a PNRS determina a reciclagem, através de compostagem, dos resíduos orgânicos, ou resíduos úmidos, diferenciados dos resíduos recicláveis secos (BRASIL, 2010).

A definição de resíduo reciclável gerou mais dificuldades entre os entrevistados, dificuldades estas já observadas nas respostas à questão 3, supracitada. Apenas $12 \%$ não souberam definir resíduo reciclável, no entanto, dos $88 \%$ restantes, $38 \%$ definiram como aquele que pode ser reutilizado.

\subsection{Resíduos recicláveis $\mathrm{x}$ não recicláveis}

$\mathrm{Na} 5^{\mathrm{a}}$ questão foi apresentada uma lista de resíduos sólidos, a maioria dos quais de provável uso comum diário dos entrevistados (Apêndice 1). Pedimos aos entrevistados que marcassem, dentre as alternativas, apenas as que representavam um resíduo sólido com potencial de ser reciclado, sem a necessidade de processos diferenciados.

Nessa lista, alguns dos itens possuem a possibilidade de ser reciclados por meio da separação dos seus componentes, causando, portanto alguma confusão. Termômetros, por exemplo, possuem vidro em sua montagem, mas, os que contém mercúrio, não podem ser considerados como produtos direta e inteiramente recicláveis. Atualmente já existe no mercado termômetros a base de materiais menos tóxicos, como aqueles compostos por uma combinação de índio (In), gálio (Ga) e estanho (Sn) (INMETRO, 2008). Os termômetros digitais também se configuram como uma opção mais sustentável, uma vez que utilizam um termistor que converte a temperatura em uma resistência elétrica conhecida, com sensibilidade equivalente ao mercúrio.

O mesmo problema pode ser observado nas pilhas e baterias que, apesar de possuírem alumínio, um material passível de reciclagem, não são diretamente recicláveis em função dos metais que as constituem. Para esse tipo de resíduo, a PNRS prevê a sua devolução à indústria, para seu reaproveitamento em seu ciclo produtivo, a chamada Logística Reversa (BRASIL, 2010). As cinco cadeias prioritárias para implementação da logística reversa são: medicamentos, embalagens em geral, embalagens de óleos lubrificantes, lâmpadas fluorescentes (de vapor de sódio, mercúrio e luz mista) e eletroeletrônicos, incluindo pilha e baterias.

Durante as entrevistas surgiram inúmeras dúvidas e uma grande curiosidade sobre o destino correto da maioria dos itens apresentados. Isso se deu, principalmente, por tais itens 
específicos não serem tão popularizados como recicláveis, uma vez que a maior parte da divulgação dessa informação é feita em termos gerais, tais como papel, plástico, metal $e$ vidro. Dos itens do questionário que não podem ser reciclados, temos: espelho, cerâmica, fita crepe, papel engordurado e fotografias. Termômetros, pilhas e baterias entram na categoria de recicláveis dependendo da constituição (no caso os termômetros) e recicláveis através da logística reversa (no caso de pilhas e baterias), Apesar das dúvidas, a grande maioria definiu corretamente os resíduos recicláveis: $65 \%$ entre os graduandos de Odontologia a $83 \%$ entre os graduandos de Ciências Biológicas.

As três questões subsequentes focaram no conhecimento dos estudantes sobre o descarte apropriado dos resíduos gerados (Apêndice 1: questões 6, 7 e 8).

\subsection{Destinação final do resíduo doméstico}

Quando indagados sobre o destino final do seu resíduo (questão 6), de 20 a 55\% dos entrevistados afirmaram desconhecer. Entre os destinos mencionados, lixão foi a opção mais citada (de 25 a 70\%), enquanto que a opção aterro ou aterro sanitário ficou entre 10 a $20 \%$ das respostas. Entre os cursos, os estudantes de medicina foram os que afirmaram, com maior veemência, o destino do seu resíduo: $70 \%$ apontaram os lixões e 10\%, os aterros.

Em âmbito nacional, em torno de $98 \%$ dos resíduos sólidos (em peso) são destinados a aterros ou lixões, o restante sendo encaminhado para compostagem e reciclagem (IBGE, 2010b). Em relação à proporção de materiais encaminhados para aterros (sanitário e controlado) e lixões, esta sofreu uma mudança significativa nos últimos 15 anos. Em 2000, $32.5 \%$ dos resíduos domiciliares e/ou públicos eram encaminhados para vazadouros a céu aberto (lixões) enquanto que 60\% eram encaminhados a aterros (IBGE, 2002). Em 2008, observou-se uma redução significativa na quantidade destinada aos lixões (menos de 20\%) acoplada a um aumento na quantidade de resíduos destinada aos aterros: 78\% (IBGE, 2010a). Essa nova realidade reflete as pressões de diversos setores da sociedade civil e políticas públicas impulsionadas pelos planos municipais, estaduais e nacional de gestão de resíduos exigidos pela PNRS.

Na cidade do Recife, durante mais de duas décadas, todo o resíduo produzido era descartado no lixão da Muribeca, desativado em 2008. Atualmente, os resíduos de Recife (2.0 toneladas/dia, em média) têm sido destinados ao Centro de Tratamento de Resíduos (CTR) Candeias, uma empresa privada, instalada no município de Jaboatão dos Guararapes, vizinho a Recife (EMLURB, 2014). Apesar de atender às normas de funcionamento de um aterro sanitário, o volume de resíduos gerados por Recife, somado aos municípios vizinhos, tem ultrapassado a capacidade do aterro, gerando uma série de problemas operacionais e políticos.

Apesar dos grandes avanços observados nos últimos 15 anos em relação à destinação final dos resíduos sólidos (lixão x aterro), os lixões ainda são uma realidade no Brasil. No caso específico da presente pesquisa, a resposta dos estudantes reflete uma falta de informação sobre o destino dos resíduos da sua cidade, que está, também, atrelada a uma falta de comprometimento e preocupação com a destinação dos seus próprios resíduos. Muitos dos estudantes que responderam lixão e até os que responderam aterro o fizeram sem total certeza de sua resposta. As respostas a essa questão ressaltam a necessidade do empenho e comprometimento mútuo para a solução desse problema crônico: a sociedade, consciente dos seus direitos e deveres, pressionando as entidades responsáveis a criar um sistema viável de disposição dos resíduos. 


\subsection{Destinação de pilhas e baterias}

Em relação às pilhas e baterias (questão 7), a maioria (81\%) tem conhecimento de que as mesmas não podem ser descartadas em recipientes comuns. Desta, $61 \%$ atribuiu o descarte diferenciado ao fato de as mesmas possuírem resíduos tóxicos (metais pesados), prejudiciais ao meio ambiente e à saúde humana. Por outro lado, os $20 \%$ restantes atribuíram à radioatividade liberada, principalmente os alunos dos cursos de Odontologia (7\%) e Educação Física (5\%) (Fig. 2).

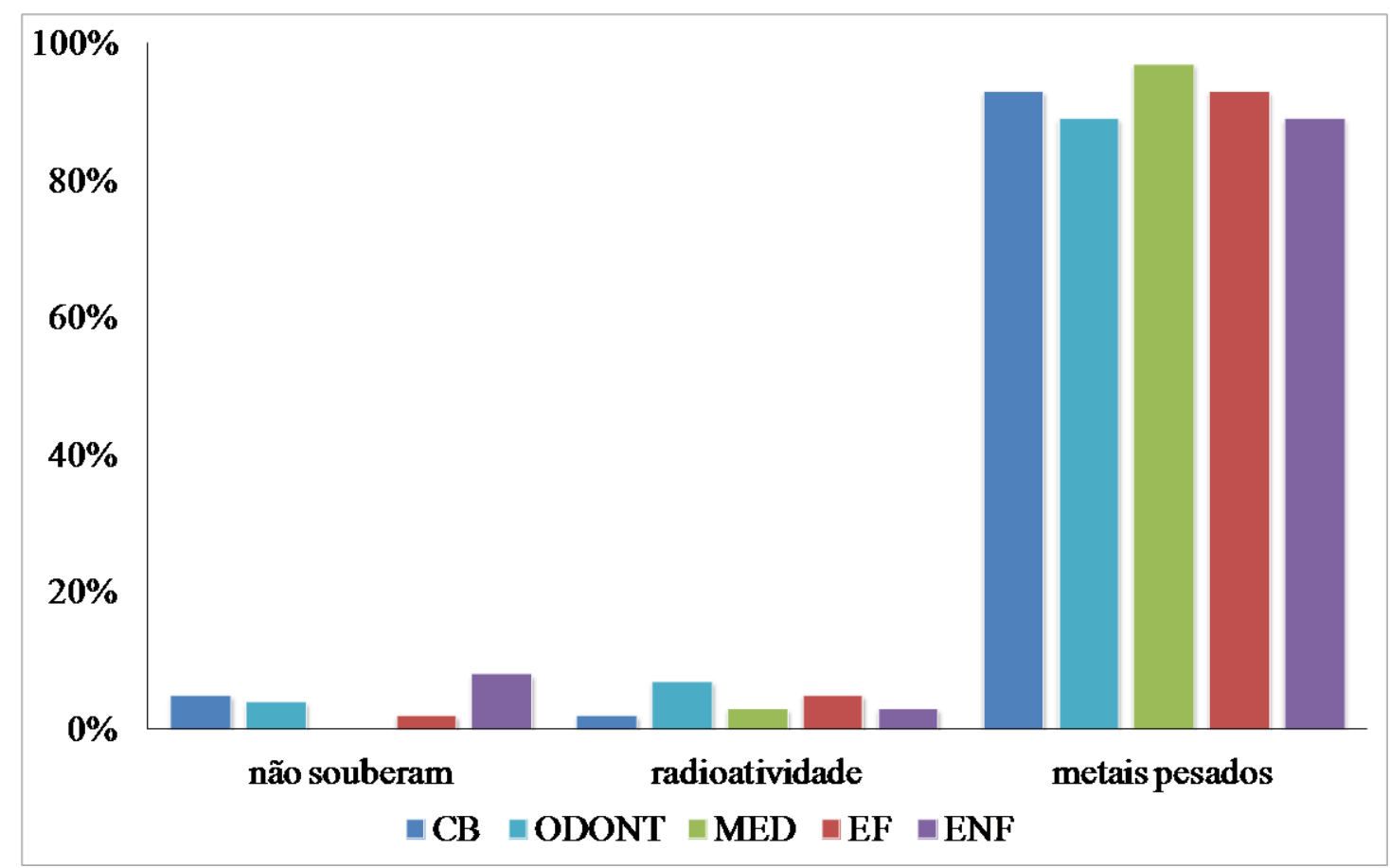

Figura 2 - Variação das respostas dos estudantes universitários sobre as justificativas ao descarte diferenciado de pilhas e baterias.

Ressalta-se que a resolução CONAMA No 257/1999 - "Estabelece que pilhas e baterias que contenham em suas composições chumbo, cádmio, mercúrio e seus compostos, tenham os procedimentos de reutilização, reciclagem, tratamento ou disposição final ambientalmente adequados" (CONAMA, 1999). Essa determinação, implementada posteriormente na PNRS através da logística reversa (BRASIL, 2010), define que esse material deve ser, portanto, entregue pelos usuários aos estabelecimentos que os comercializam ou à rede de assistência técnica autorizada pelas respectivas indústrias, de modo a garantir sua destinação adequada.

Apesar de a razão pela qual o descarte deva ser diferenciado não ser totalmente compreendida pelos estudantes entrevistados, o fato de a grande maioria saber que não deve descartar em recipientes comuns já representa um avanço no conhecimento da gestão desses resíduos.

\subsection{Destinação do material utilizado em laboratório}

Em relação à destinação final do material utilizado nos laboratórios da Universidade: luvas, seringas, agulhas, gazes, máscaras e toucas (Questão 8), a grande maioria declarou utilizar o descarte correto: material biológico ou infectocontagioso para os materiais contaminados e material perfurocortante para seringas e agulhas. Apenas $18 \%$ declararam 
utilizar recipientes comuns para o descarte, sendo a maioria dos cursos de Educação Física $(8 \%)$ e Odontologia (6\%). A totalidade dos estudantes dos cursos de Enfermagem e Medicina afirmou realizar o descarte correto do material. A orientação dos professores e a sinalização nos laboratórios foram apontadas como fatores principais para a conscientização dos alunos.

\subsection{Responsáveis pela coleta seletiva}

Quando perguntados se havia algum tipo de coleta de material reciclável próximo a sua moradia (Questão 9), 43\% confirmaram a existência de coleta seletiva. Os catadores foram os mais citados, em $36 \%$ dos casos, seguidos dos pontos fixos de coleta, como igrejas, postos de gasolina e supermercados (13\%). Caminhões de coleta seletiva foram os menos citados, apenas $7 \%$ dos entrevistados mencionaram observar a passagem desses caminhões em seu bairro.

Em um âmbito nacional, em torno de $32 \%$ dos resíduos sólidos urbanos coletados no Brasil consistem em material reciclável (metais, papel e papelão, plástico e vidro). No entanto, a coleta seletiva formal é responsável por uma pequena fração da reciclagem desses materiais: menos de $1 \%$ para metais e menos de $20 \%$ para os plásticos. Os catadores (i.e., coleta seletiva informal) são, de fato, os principais responsáveis pela manutenção da reciclagem no país (BRASIL, 2012).

Em um contexto mais local, segundo a Empresa de Manutenção e Limpeza Urbana da Cidade do Recife (EMLURB), existe coleta semanal de resíduos recicláveis em 45 dos 94 bairros que compõem a cidade. Além de dispor de 107 depósitos de coleta seletiva espalhados em pontos estratégicos da cidade (EMLURB, 2014). Apesar dos grandes avanços nacionais em relação à gestão de resíduos sólidos após a implementação da PNRS, desde a coleta até a reciclagem e reincorporação na cadeia produtiva, para uma cidade de mais de 1,5 milhões de habitantes distribuídos em um território de 218,5 km² como Recife (IBGE, 2010b), trata-se de uma ação ainda incipiente para as suas dimensões.

O fato de $43 \%$ dos entrevistados confirmarem a existência de coleta seletiva, mas apenas 7\% mencionar a passagem de caminhões aponta para algumas questões importantes relativas à melhoria na implementação efetiva da coleta seletiva. De fato, a pesquisa demonstra que os maiores responsáveis pela reciclagem na cidade são os catadores, o que já foi observado em âmbito nacional (BRASIL, 2012). Além do número de bairros contemplados com a coleta seletiva formal ser limitado, a periodicidade de passagem dos caminhões coletores e a quantidade de depósitos de coleta são insuficientes para atender às necessidades da cidade. Assim, a percepção dos estudantes reflete, claramente, a dimensão do processo de coleta seletiva na região metropolitana do Recife, não muito diferente do observado em outras cidades brasileiras (BRASIL, 2012).

\subsection{Participação ativa dos estudantes na separação dos resíduos sólidos}

As duas questões seguintes focaram na participação ativa dos estudantes na separação dos resíduos sólidos (Apêndice 1, questões 10 e 11).

Em relação à separação dos resíduos domésticos, $50 \%$ dos entrevistados nunca separaram, $29 \%$ separam e $21 \%$ afirmaram já ter separado, mas não mais, atualmente. Os últimos relataram que não separam mais por vários motivos: mudança de moradia, onde não há mais a coleta seletiva, resistência dos outros membros da família a separar os resíduos e distância dos postos de reciclagem. Grande parte dos estudantes que fazem a separação tem coleta seletiva em seus condomínios. 
Analisando por curso, nota-se que os alunos dos cursos de Educação Física e Enfermagem são mais participativos no que se refere à separação dos resíduos domésticos (35 a 40\%), mais até do que os estudantes do curso de Ciências Biológicas, de onde se esperava uma atitude mais engajada nesse quesito (Fig. 3).

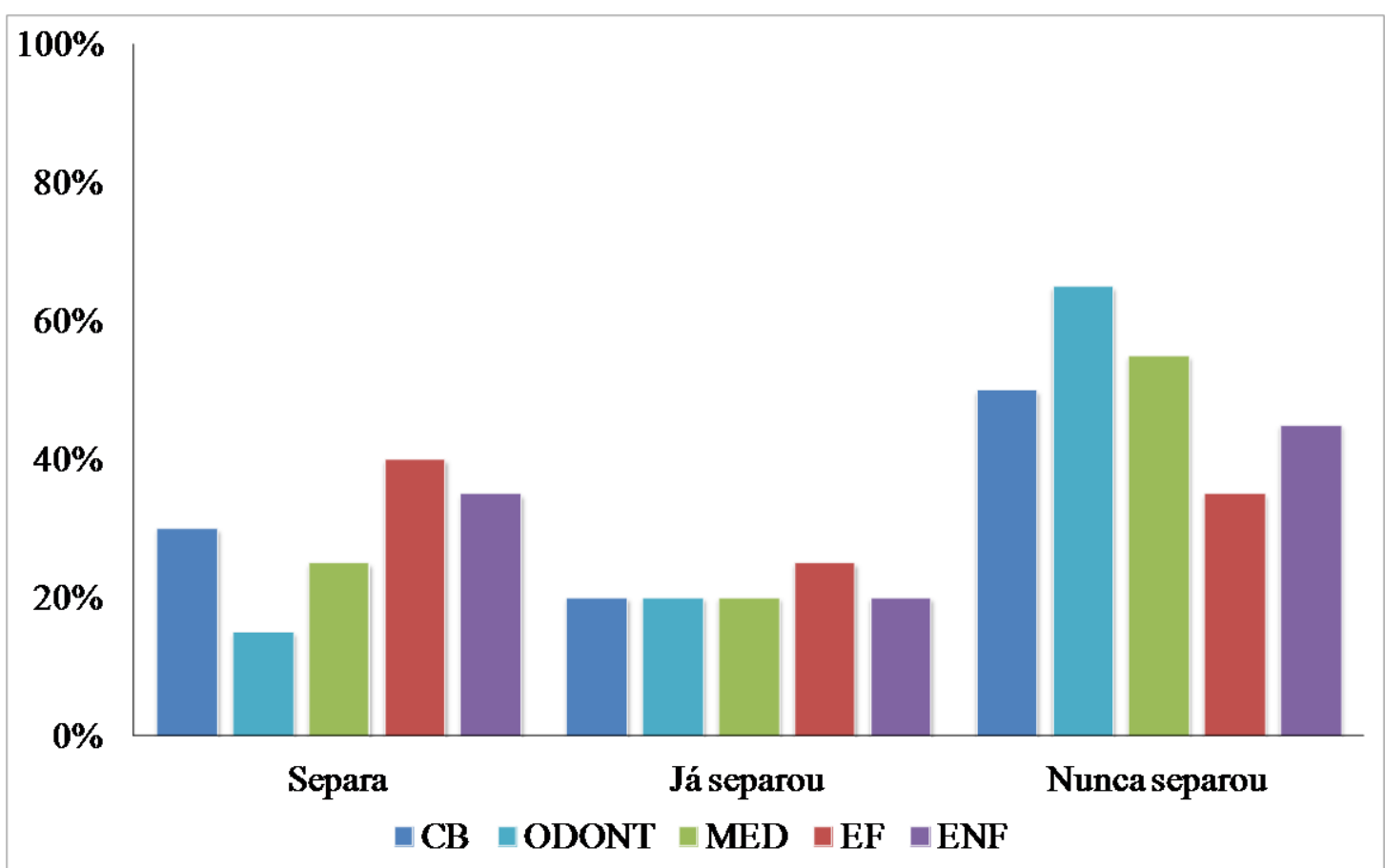

Figura 3 - Variação das respostas dos estudantes universitários sobre a separação dos resíduos domésticos

Notamos, aqui, uma grande falta de participação dos estudantes na coleta seletiva em si. De modo geral, vemos que eles têm conhecimento suficiente sobre as questões ambientais relacionadas à geração e destinação dos resíduos sólidos, que, no entanto não é revertido para as ações. Sugerimos que essa apatia talvez possa ser percebida na sociedade como um todo, prevalecendo a atitude de culpabilizar apenas os governantes pelos problemas locais que poderiam ser mais facilmente resolvidos se houvesse uma maior ação (e pressão) efetiva da sociedade.

Quanto ao destino do óleo de cozinha, apesar de não se tratar de um resíduo sólido, achamos pertinente incluí-lo neste estudo por ser bastante prejudicial ao ambiente (questão 11). Dos estudantes entrevistados, $89 \%$ demonstraram saber da importância em separá-lo dos demais resíduos. Destes, a maioria (43\%) apontou o impacto ambiental causado pelo óleo como fator principal que justifique sua separação. Outros fatores citados foram: a possibilidade de reutilização do óleo, por exemplo para a fabricação de sabão (11\%), o problema do entupimento dos canos $(10 \%)$ e a dificuldade na reciclagem de outros produtos quanto misturados ao óleo (7\%). O restante (18\%) declarou não saber o motivo da separação, apesar de reconhecer sua importância.

De fato, a contaminação dos corpos de água pelo despejo do óleo in natura (acidental ou intencional) é considerada um dos mais graves impactos nos ambientes aquáticos. Mas a obstrução dos encanamentos e a inviabilização do tratamento dos esgotos domésticos também se somam aos prejuízos gerados por essa atividade (CASTELLANELLI, 2008).

Apesar do conhecimento da maioria sobre a importância da separação e destinação adequada do óleo de cozinha, apenas $7 \%$ (igualmente distribuidos entre os cursos) efetivamente separam o óleo e enviam para um receptor. Novamente, percebemos aqui a 
distância entre o saber e o fazer por parte dos estudantes entrevistados. Na cidade onde foi desenvolvido o presente estudo (Recife, PE) existem vários postos de coleta de óleo, como, por exemplo, em supermercados e postos de gasolina, como foi informado posteriormente aos entrevistados. No entanto, poucos tinham conhecimento desses locais.

\subsection{Autoavaliação final}

O questionário foi encerrado com uma autoavaliação do conhecimento sobre os resíduos sólidos (questão 12), momento no qual os entrevistados puderam emitir suas opiniões sobre o estudo como um todo e fazer uma reflexão sobre seu conhecimento e suas ações.

Dos entrevistados, $24 \%$ consideraram possuir um bom conhecimento sobre o tema (pontuação entre 8-10), mas a maioria (71\%) classificou seu conhecimento como regular (entre 5 e 7 pontos). Apenas 5\% dos entrevistados se posicionaram abaixo de 4 pontos, considerado fraco. Comparando esses resultados com a primeira autoavaliação (questão 2), de $43 \%$ que consideraram ter um bom conhecimento sobre o tema meio ambiente, apenas $24 \%$ se mantiveram nessa pontuação em relação ao tema resíduos sólidos. O último, apesar de ser um tema mais específico do que o tema meio ambiente, avaliamos essa diferença como o resultado da reflexão sobre o questionário. Muitos entrevistados comentaram sobre a dificuldade em definir alguns conceitos, à primeira vista, simples.

A contraposição entre os saberes e as atitudes, percebida em muitos momentos ao longo do presente estudo, foi comentada por grande parte dos entrevistados, com frases semelhantes a - tenho bastante consciência sobre o assunto, porém ter conhecimento sem prática torna o resultado nulo - conforme relato de uma das entrevistadas.

Outro ponto relevante, levantado por alguns entrevistados, refere-se à necessidade de se incluir disciplinas que abordem conteúdos mais voltados para questões ambientais nos diversos cursos, não apenas em Ciências Biológicas, para suprir as lacunas percebidas no questionário. De fato, a educação ambiental, como temática transdisciplinar, deve, por definição, fazer parte do currículo de todos os cursos.

\section{Conclusões}

A metodologia aplicada no presente estudo, além de avaliar o conhecimento e atuação dos estudantes, teve o papel de estimular a elucidação das dúvidas pessoais e o compartilhamento de vivências e experiências por parte dos entrevistados.

Contrariando as expectativas, não foi observada diferença em relação ao conhecimento ou à postura ativa dos estudantes do curso de Ciências Biológicas comparados aos demais, apesar de os mesmos terem apontado a Universidade como principal fonte de informação para a obtenção de conhecimento sobre assuntos relacionados ao meio ambiente. Grande parte do conhecimento adquirido por esses estudantes, independente do curso, advém do ensino fundamental e médio, confirmando o papel crucial da educação na construção dos saberes e da consciência ecológica do cidadão, desde a mais tenra infância. A Universidade, por outro lado, não se mostrou suficientemente influente na conscientização dos estudantes.

A falta de iniciativa observada em relação ao tratamento individual dos resíduos sólidos, apesar do conhecimento teórico bastante aprofundado, revela a apatia generalizada da sociedade. O conhecimento sem a ação não tem o alcance necessário para uma mudança de comportamento e a Universidade precisa ir além do papel de formar profissionais em suas áreas específicas. Um meio de socialização e compartilhamento de saberes e opiniões tão profícuo como o universitário deve ser melhor aproveitado para a formação de cidadãos conscientes e transformadores do ambiente em que vivem. 
Finalmente, o presente estudo mostrou que os estudantes entrevistados de todos os cursos da área de saúde estão bastante receptivos a novas ideias e práticas sustentáveis, o que torna totalmente viável a aplicação de projetos práticos de educação ambiental voltados à gestão dos resíduos sólidos na Universidade foco desta pesquisa, objetivo final deste estudo.

\section{Referências}

ADÃO, N.M.L. A Práxis na Educação Ambiental. Revista Eletrônica do Mestrado em Educação Ambiental, Rio Grande, v.14, p.74-76, 2005.

BRANDALISE, L.T. et al. A percepção e o comportamento ambiental dos universitários em relação ao grau de educação ambiental. Gestão \& Produção, São Carlos, v.16, n.2, p.273-285, 2009.

BRASIL. Lei $\mathrm{n}^{\circ}$ 12.305, de 02 de agosto de 2010. Diário Oficial da União, 03 de agosto de 2010, Brasília, 2010.

BRASIL. Plano Nacional de Resíduos Sólidos. Brasília: Ministério do Meio Ambiente, 2012.

CASTELLANELLI, C.A. Estudo da viabilidade de produção do biodiesel, obtido através do óleo de fritura usado, na cidade de Santa Maria - RS. 2008. 111f. Dissertação (Mestrado em Engenharia de Produção) - Centro de Tecnologia, Universidade Federal de Santa Maria, Santa Maria, 2008.

CONSELHO NACIONAL DO MEIO AMBIENTE - CONAMA. Resolução $n^{\circ}$ 257, de 22 de julho de 1999. Diário Oficial da União. Brasília, 1999.

EMPRESA DE MANUTENÇÃO E LIMPEZA URBANA - EMLURB. Coleta Seletiva. Disponível em: www2.recife.pe.gov.br/projetos-e-acoes/acoes/coleta-seletiva/ Acesso em 15 out. 2014.

INSTITUTO BRASILEIRO DE GEOGRAFIA E ESTATÍSTICA - IBGE. Pesquisa Nacional de Saneamento Básico 2000. Rio de Janeiro: IBGE, 2002.

INSTITUTO BRASILEIRO DE GEOGRAFIA E ESTATÍSTICA - IBGE. Pesquisa Nacional de Saneamento Básico 2008. Rio de Janeiro: IBGE, 2010a.

INSTITUTO BRASILEIRO DE GEOGRAFIA E ESTATÍSTICA - IBGE. Censo Demográfico 2010 - Recife: evolução populacional. Rio de Janeiro: IBGE, 2010b.

INSTITUTO NACIONAL DE METROLOGIA, QUALIDADE E TECNOLOGIA INMETRO. Portaria Inmetro/Dimel $n^{o}$ 52, de 05 de março de 2008. Disponível em: <www.inmetro.gov.br>. Acesso em 15 out. 2014.

JACOBI, P. Educação Ambiental, Cidadania e Sustentabilidade. Cadernos de Pesquisa, São Paulo, s/v, n. 118, p.189-205, 2003.

TAUCHEN, J.; BRANDILI, L.L. A gestão ambiental em instituições de ensino superior: modelo para implantação em campus universitário. Gestão \& Produção, São Carlos, v. 13, n. 3, p. 503-515, 2006. 
Artigo recebido em 02/08/2014

Aceite em 08/04/2015 
Apêndice

\section{Questionário}

Nome:

Idade:

Curso/Período:

Bairro:

E-mail:

1. O que mais o incomoda nos lugares que você frequenta na cidade?

2. De 0 a 10, como você avalia seu conhecimento com relação ao tema meio ambiente? Onde você obteve esse conhecimento?

3. O que você entende por reciclagem e coleta seletiva?

4. Qual a diferença entre resíduos orgânicos e recicláveis?

5. Dos resíduos seguintes, quais podem ser reciclados?

Garrafa de Vidro - Cerâmica - Canos de PVC - Pilhas e Baterias - Garrafa PET - Alumínio Espelho - Pregos - Fita Crepe - Papel Ofício - Fotografias - Potes de Plástico - Termômetro Jornal - Papel Engordurado - Tampinha de Refrigerante

6. Você sabe qual o destino final dos resíduos gerados em sua residência?

7. Pilhas e baterias podem ser descartadas em recipientes comuns? Por quê?

8. Como você descarta os materiais utilizados no seu curso: luvas, seringas, gazes, agulhas, máscaras e/ou toucas?

9. Existe coleta de material reciclável onde você mora?

( ) Sim ( ) Não

No caso afirmativo, assinale os agentes de coleta:

( ) Catadores

( ) Caminhão de coleta seletiva

( ) Ponto de coleta próximo

( ) Outros

10. Você já separou ou separa os seus resíduos em casa?

11. Sobre o óleo de cozinha, você acha importante separá-lo dos demais resíduos? Por quê? Você separa? No caso afirmativo, como descarta?

12. De 0 a 10, como você avalia seu conhecimento com relação ao tema resíduos sólidos? 